\title{
Influence of gangue existing states in iron ores on the formation and flow of liquid phase during sintering
}

\author{
Guo-liang Zhang, Sheng-li Wu, Shao-guo Chen, Bo Su, Zhi-gang Que, Chao-gang Hou \\ School of Metallurgical and Ecological Engineering, University of Science and Technology Beijing, Beijing 100083, China \\ (Received: 21 November 2013; revised: 17 January 2014; accepted: 29 January 2014)
}

\begin{abstract}
Gangue existing states largely affect the high-temperature characteristics of iron ores. Using a micro-sintering method and scanning electron microscopy, the effects of gangue content, gangue type, and gangue size on the assimilation characteristics and fluidity of liquid phase of five different iron ores were analyzed in this study. Next, the mechanism based on the reaction between gangues and sintering materials was unraveled. The results show that, as the $\mathrm{SiO}_{2}$ levels increase in the iron ores, the lowest assimilation temperature (LAT) decreases, whereas the index of fluidity of liquid phase (IFL) increases. Below $1.5 \mathrm{wt} \%, \mathrm{Al}_{2} \mathrm{O}_{3}$ benefits the assimilation reaction, but higher concentrations proved detrimental. Larger quartz particles increase the $\mathrm{SiO}_{2}$ levels at the local reaction interface between the iron ore and CaO, thereby reducing the LAT. Quartz-gibbsite is more conductive to assimilation than kaolin. Quartz-gibbsite and kaolin gangues encourage the formation of liquid-phase low- $\mathrm{Al}_{2} \mathrm{O}_{3}-\mathrm{SFCA}$ with high IFL and high- $\mathrm{Al}_{2} \mathrm{O}_{3}-\mathrm{SFCA}$ with low IFL, respectively.
\end{abstract}

Keywords: iron ores; ore sintering; assimilation; liquid phase; fluidity

\section{Introduction}

With the development of high-grade burden and large-scale of a blast furnace (BF), sinter strength plays an increasingly important role on the running conditions of BF. To improve sinter quality, the properties of sintering raw materials must be investigated, especially the high temperature characteristics of iron ores [1]. According to reports of $\mathrm{Wu}$ et al. [2-5], iron ores exhibit five high-temperature characteristics that accurately reflect the behavior and role in the sintering process. Differences in assimilation characteristics of various iron ores have been also studied [6-7]. In addition, Kasai et al. [8-9] studied the influence of $\mathrm{Al}_{2} \mathrm{O}_{3}$ content and the particle size of iron ores and limestone on the melt-formation process. The viscosity of melt formed during iron ore sintering was investigated by Machida et al. [10]. Hsien and Whiteman [11] studied the effect of raw material composition on the mineral phase of iron ore sinter. However, the influence of gangue existing states in iron ores on the assimilation characteristics and the fluidity of liquid phase in the sintering process have been little investigated.

In the present study, fundamental studies were conducted to gain insight on the influence of gangue existing states in iron ores on the assimilation characteristic and fluidity of liquid phase, by analyzing the lowest assimilation temperature (LAT) and the index of fluidity of liquid phase (IFL) using a micro-sintering method. Based on the obtained results, the mechanisms were discussed, underlying the LAT and IFL of pure reagent mixtures with different gangue types.

\section{Experiments}

\subsection{Samples}

In the present study, five different types of iron ores were used, and details on the chemical composition of iron ores are summarized in Table 1. Ore-A, Ore-B, and Ore-C, comprising limonite, a mixed iron ore, and hematite, respectively, were produced in Australia, while Ore-D and Ore-E were hematite iron ores produced in Brazil. In addition, $\mathrm{Fe}_{2} \mathrm{O}_{3}, \mathrm{CaO}, \mathrm{SiO}_{2}, \mathrm{Al}_{2} \mathrm{O}_{3}$ pure reagent ( $\mathrm{AR}, 99 \%$ ), and kaolin pure reagent $(\mathrm{CR})$ were also used. The chemical composition of kaolin pure reagent was $\mathrm{Fe}_{2} \mathrm{O}_{3}=0.35 \mathrm{wt} \%, \mathrm{SiO}_{2}=$ $46.69 \mathrm{wt} \%, \mathrm{Al}_{2} \mathrm{O}_{3}=37.80 \mathrm{wt} \%$, and LOI $=13.58 \mathrm{wt} \%$.

Corresponding author: Sheng-li Wu E-mail: wushengli@ustb.edu.cn

(C) University of Science and Technology Beijing and Springer-Verlag Berlin Heidelberg 2014 
Table 1. Chemical compositions of iron ore samples wt $\%$

\begin{tabular}{ccccccc}
\hline Iron ore & $\mathrm{TFe}$ & $\mathrm{SiO}_{2}$ & $\mathrm{CaO}$ & $\mathrm{Al}_{2} \mathrm{O}_{3}$ & $\mathrm{MgO}$ & LOI \\
\hline Ore-A & 58.07 & 5.30 & 0.03 & 1.55 & 0.05 & 10.18 \\
Ore-B & 60.84 & 3.96 & 0.03 & 2.26 & 0.05 & 6.30 \\
Ore-C & 62.44 & 4.43 & 0.03 & 2.37 & 0.05 & 3.35 \\
Ore-D & 64.62 & 4.69 & 0.03 & 0.79 & 0.08 & 1.47 \\
Ore-E & 65.26 & 1.92 & 0.03 & 1.27 & 0.03 & 2.08 \\
\hline
\end{tabular}

\subsection{Assimilation}

The influence of gangue existing states on the assimilation characteristics of iron ores were clarified by assimilation reaction tests. Figs. 1, 2, and 3 schematize the micro-sintering equipment, the temperature system and atmosphere condition of the assimilation reaction test, and the assimilation states, respectively. The LAT was defined as the reaction temperature at which slight liquid phase was formed in the reaction between the iron ore and $\mathrm{CaO}$ pure reagent. Iron ores of different particle size were ground to $-0.15 \mathrm{~mm}$ by a sealed crusher. Materials were shaped into

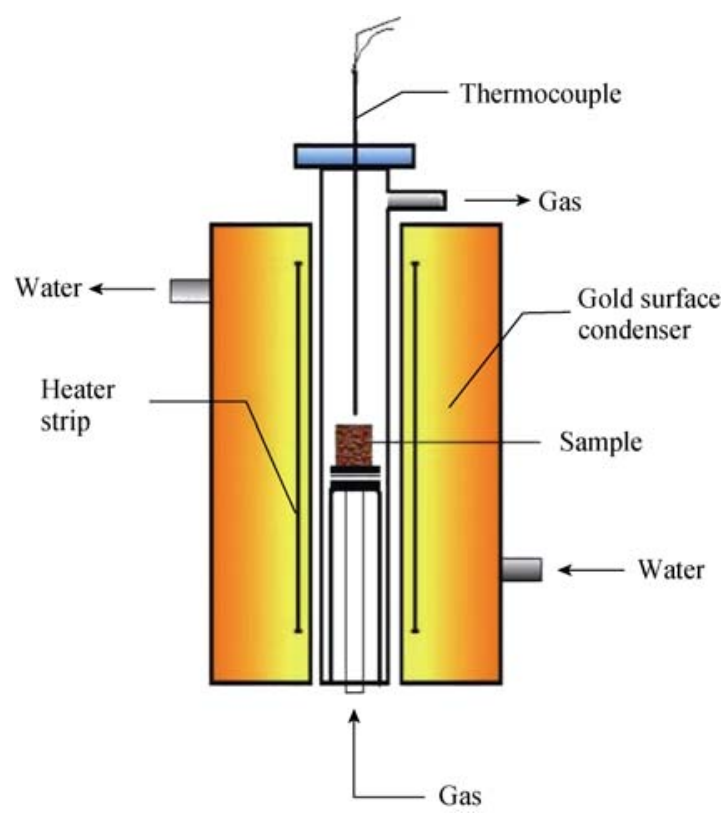

Fig. 1. Schematic of the micro-sintering equipment.

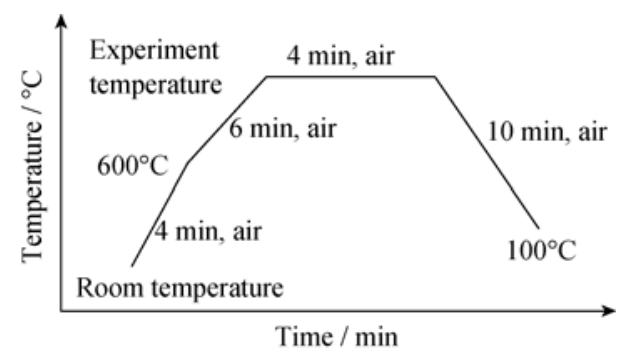

Fig. 2. Temperature system and atmosphere condition of the assimilation test.

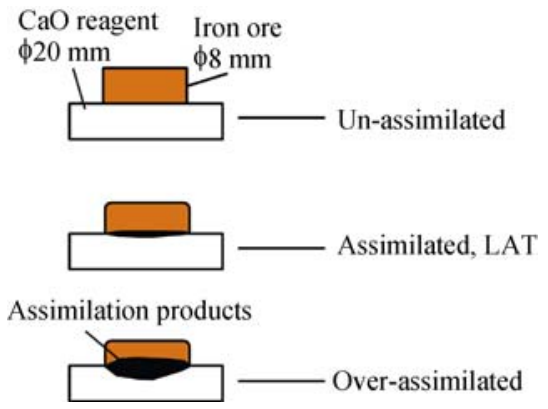

Fig. 3. Schematic illustration of assimilation states.

tablets in two steel molds under a pressure of $15 \mathrm{MPa}$ for about $2 \mathrm{~min}$. The $\mathrm{CaO}$ and iron ore tablets weighed $2.0 \mathrm{~g}$ and $0.8 \mathrm{~g}$, respectively. Both tablets were subsequently sintered in the micro-sintering equipment.

\subsection{Fluidity of liquid phase}

To clarify the influence of gangue existing states on the fluidity of liquid phase during sintering, the index of fluidity of liquid phase was evaluated in fluidity tests of the five iron ores mixed with pure $\mathrm{CaO}$ reagent at a binary basicity of 4.0 . The fine mixture (approximately $0.8 \mathrm{~g}$ ) was shaped into a tablet in a steel mold pressurized at $15 \mathrm{MPa}$ for approximately $2 \mathrm{~min}$. The equipment, temperature, and atmosphere used to characterize the fluidity of liquid phase was essentially the same as that used in the assimilation reaction tests with the following exceptions: the experimental temperature of fluidity tests was $1280^{\circ} \mathrm{C}$, and the atmosphere was changed to $\mathrm{N}_{2}$ at temperatures exceeding $600^{\circ} \mathrm{C}$. Fig. 4 is a schematic of the flow state of liquid phase. Comparing the areas of samples before and after sintering tests, the IFL is calculated as

$\mathrm{IFL}=(\mathrm{FA}-\mathrm{OA}) / \mathrm{OA}$

where OA and FA is the original area and the flowing area before and after the sinter test, respectively.

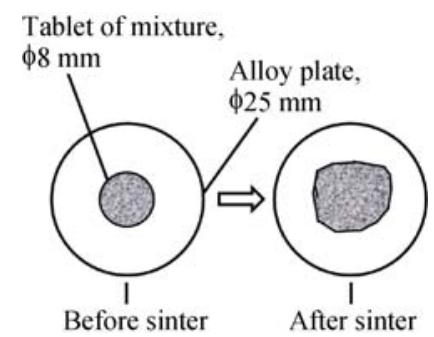

Fig. 4. Schematic of liquid-phase flow state.

\section{Results}

Fig. 5 compares the LATs of the five iron ores. The highest and lowest LAT are measured for Ore-D and Ore-A, respectively. 


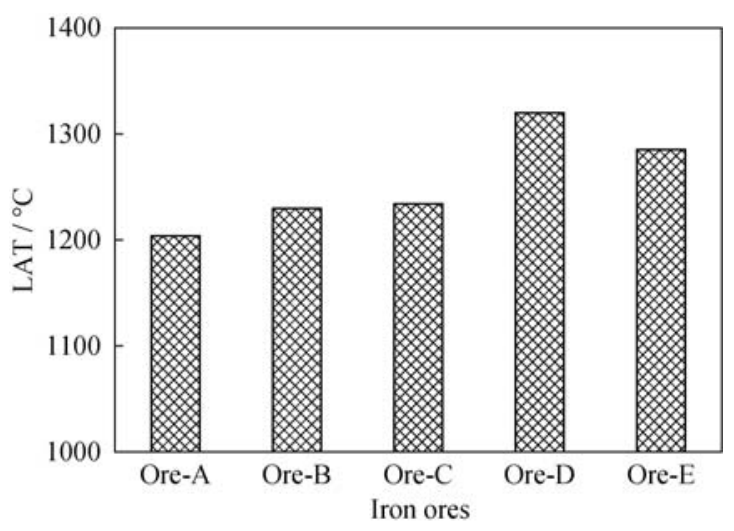

Fig. 5. The lowest assimilation temperatures of iron ores.

The IFLs of the five iron ores are compared in Fig. 6. Here, Ore-A yields the highest IFL, while the lowest IFL is obtained by Ore-E.

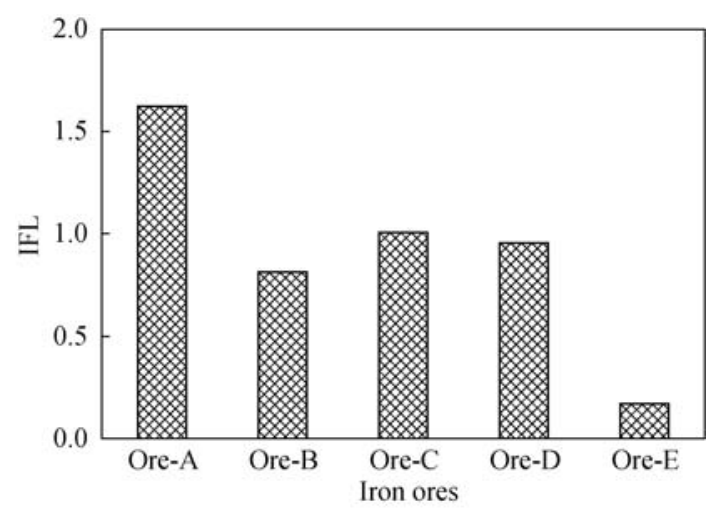

Fig. 6. Indexes of fluidity of liquid phase of iron ores.

\section{Discussion}

\subsection{Influence of gangue existing states on the LAT of iron ores}

In the present study, the gangue existing states were reflected by three indexes; gangue content (including $\mathrm{SiO}_{2}$ and $\mathrm{Al}_{2} \mathrm{O}_{3}$ contents), gangue particle size (especially that of the predominant material, quartz), and gangue type (whether quartz, gibbsite, or kaolin).

The relationship between $\mathrm{SiO}_{2}$ content and the LAT of the iron ores is plotted in Fig. 7. As evidenced in the figure, except Ore-D, the LAT is a linearly decrease as a function of $\mathrm{SiO}_{2}$ content, consistent with previous reports [12-13]. According to thermodynamic data [14], the melting point of $\mathrm{Fe}_{2} \mathrm{O}_{3} \cdot \mathrm{CaO}(\mathrm{CF})$ is $1216^{\circ} \mathrm{C}$. As the $\mathrm{SiO}_{2}$ content increases, a eutectic mixture $\mathrm{CaO} \cdot \mathrm{SiO}_{2}-\mathrm{CaO} \cdot \mathrm{Fe}_{2} \mathrm{O}_{3}-\mathrm{CaO} \cdot 2 \mathrm{Fe}_{2} \mathrm{O}_{3}$ is formed. Since the melting point of the eutectic mixture $\left(1192^{\circ} \mathrm{C}\right)$ is lower than that of $\mathrm{CF}$, the assimilation temperature of $\mathrm{Fe}_{2} \mathrm{O}_{3}-\mathrm{SiO}_{2}$ mixture is reduced. Thus, as the $\mathrm{SiO}_{2}$ content increases, the lowest assimilation temperature of the iron ore reduces.

Conversely, Ore-A and Ore-D have the similar $\mathrm{SiO}_{2}$ content, but their LAT values vary widely. The anomalously high LAT of Ore-D may result from the different quartz particle size, as shown in Fig. 8. Here, although dense quartz is present in both iron ores, the quartz particle size in Ore-A exceeds $100 \mu \mathrm{m}$, while it is below $30 \mu \mathrm{m}$ in Ore-D. The large quartz particle size in Ore-A increases the topo- $\mathrm{SiO}_{2}$ content at the assimilation reaction interface, thereby lowering LAT, compared with Ore-D with the small quartz particles.

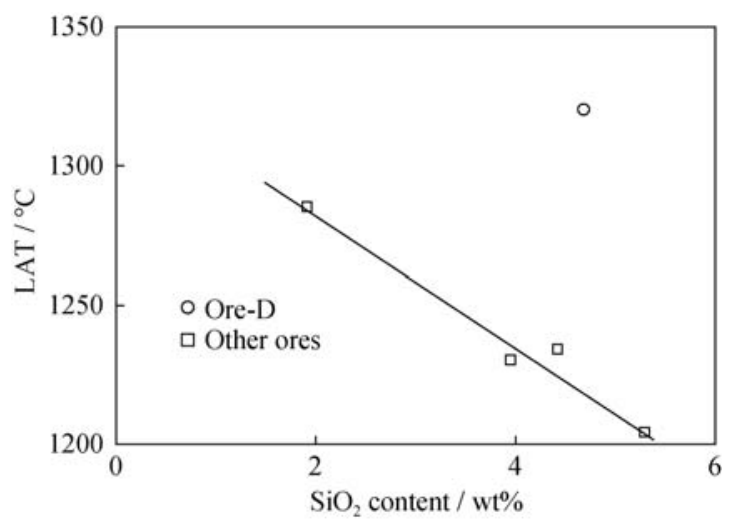

Fig. 7. Relationship between $\mathrm{SiO}_{2}$ content and the LAT of iron ore.

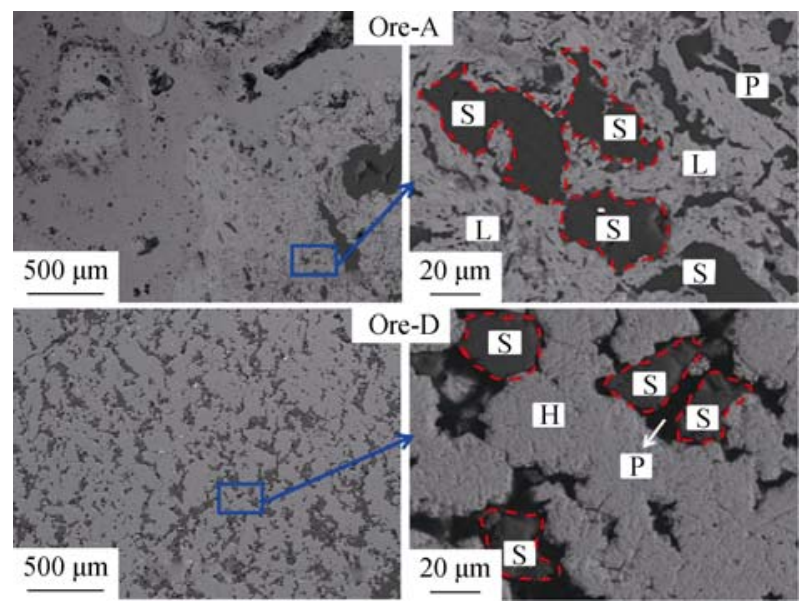

Fig. 8. Quartz particle size in Ore-A and Ore-D ( $\mathrm{L}-$ limonite, $\mathrm{H}$-hematite, $\mathrm{S}-\mathrm{SiO}_{2}$, and $\mathrm{P}$ - pore).

Fig. 9 plots the relationship between $\mathrm{Al}_{2} \mathrm{O}_{3}$ content and the LAT of iron ores. In this figure, the LAT decreases with increasing $\mathrm{Al}_{2} \mathrm{O}_{3}$ content up to $1.5 \mathrm{wt} \%$, and increases thereafter. At low levels of $\mathrm{Al}_{2} \mathrm{O}_{3}$, the reduced LAT may be attributed to the formation of SFCA, a compound with relative low melting point. Once the $\mathrm{Al}_{2} \mathrm{O}_{3}$ content exceeds $1.5 \mathrm{wt} \%$, the SFCA contains superfluous high-melting point $\mathrm{Al}_{2} \mathrm{O}_{3}$, which raises the LAT. Furthermore, Guo et al. [15] reported 
that $\mathrm{Al}_{2} \mathrm{O}_{3}$ in the $\mathrm{Fe}_{2} \mathrm{O}_{3}-\mathrm{Al}_{2} \mathrm{O}_{3}$ mixture blocked the inter-diffusion of $\mathrm{Fe}_{2} \mathrm{O}_{3}$ and $\mathrm{CaO}$, decreasing the formation speed of calcium ferrite. In addition, because the standard Gibbs free energy of $\mathrm{CaO} \cdot 2 \mathrm{Al}_{2} \mathrm{O}_{3}$ is small, $\mathrm{CaO}$ shows a higher affinity to $\mathrm{Al}_{2} \mathrm{O}_{3}$ than $\mathrm{Fe}_{2} \mathrm{O}_{3}$, further reducing the formation rate of calcium ferrite.

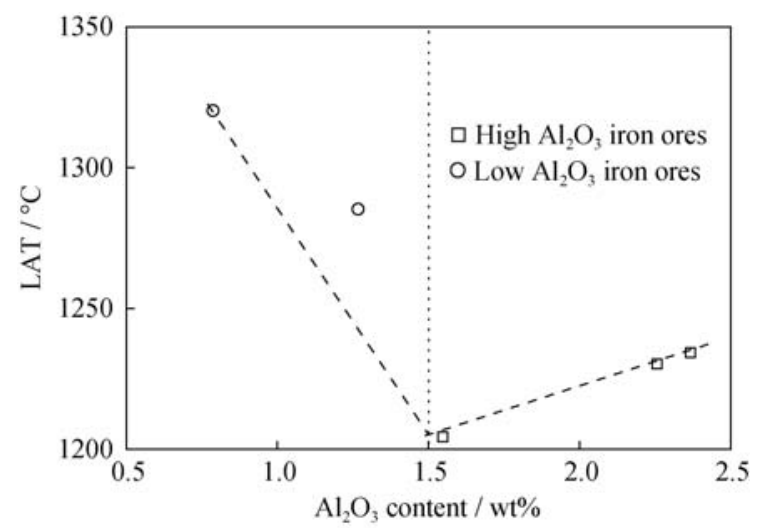

Fig. 9. Relationship between $\mathrm{Al}_{2} \mathrm{O}_{3}$ content and the LAT of iron ores.

To clarify the influence of gangue type on the assimilation temperature, the iron ores were subjected to X-ray diffraction (XRD) analysis and pure reagent simulating tests. The XRD patterns of the five iron ores are displayed in Fig. 10. Gangues in Ore-A and Ore-D chiefly comprise quartz and gibbsite, while those in Ore-B, Ore-C and Ore-E are kaolin, quartz, and gibbsite. Table 2 lists the mixing conditions of materials in the pure reagent simulating tests of assimilation. Schemes 1 and 2 simulate the gangue existing states of quartz and gibbsite with $\mathrm{SiO}_{2}$ and $\mathrm{Al}_{2} \mathrm{O}_{3}$ pure reagents. The $\mathrm{SiO}_{2} / \mathrm{Al}_{2} \mathrm{O}_{3}$ ratio by mass in schemes 1 and 2 is 1.24. The $\mathrm{SiO}_{2} / \mathrm{Al}_{2} \mathrm{O}_{3}$ ratio in kaolin used in schemes 3 and 4 is also 1.24. Schemes 1 and 3 are low gangue mixtures of chemical composition $\left(\mathrm{Fe}_{2} \mathrm{O}_{3}=98.30 \mathrm{wt} \%, \mathrm{SiO}_{2}=0.94 \mathrm{wt} \%\right.$, and $\mathrm{Al}_{2} \mathrm{O}_{3}=0.76 \mathrm{wt} \%$ ), while schemes 2 and 4 are high gangue mixtures of chemical composition $\left(\mathrm{Fe}_{2} \mathrm{O}_{3}=\right.$ $96.60 \mathrm{wt} \%, \mathrm{SiO}_{2}=1.88 \mathrm{wt} \%, \mathrm{Al}_{2} \mathrm{O}_{3}=1.52 \mathrm{wt} \%$ ). Fig. 11 displays the results of the pure reagent simulating tests. The quartz-gibbsite (Q-G) gangue existing state yields a lower LAT than that of kaolin $(\mathrm{K})$ gangue.

\subsection{Influence of gangue existing state on the IFL of iron ores}

The relationship between $\mathrm{SiO}_{2}$ content and the IFL of the iron ore is plotted in Fig. 12. The IFL linearly increases with increasing $\mathrm{SiO}_{2}$ content. Under the condition of certain binary basicity, more $\mathrm{CaO}$ is added in the iron ore, and the $\mathrm{CaO}$ mixture with the increase of $\mathrm{SiO}_{2}$ content of iron ore

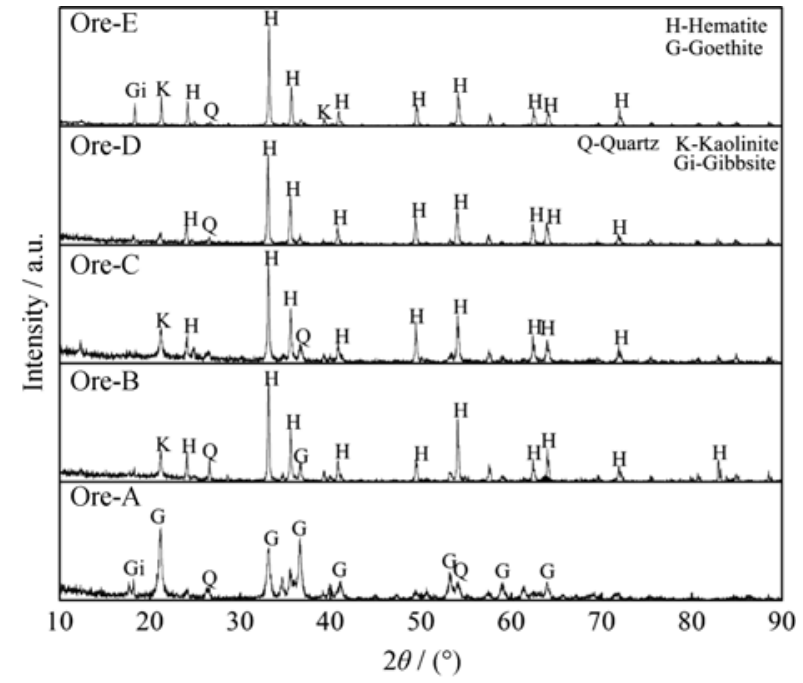

Fig. 10. XRD patterns of the five iron ores.

Table 2. Mixing conditions in simulating tests of assimilation

\begin{tabular}{cccccc} 
& & & & & wt $\%$ \\
\hline Scheme & $\mathrm{Fe}_{2} \mathrm{O}_{3}$ & $\mathrm{SiO}_{2}$ & $\mathrm{Al}_{2} \mathrm{O}_{3}$ & Kaolin & Total \\
\hline Scheme 1 & 98.30 & 0.94 & 0.76 & 0 & 100 \\
Scheme 2 & 96.60 & 1.88 & 1.52 & 0 & 100 \\
Scheme 3 & 98.00 & 0 & 0 & 2 & 100 \\
Scheme 4 & 96.00 & 0 & 0 & 4 & 100 \\
\hline
\end{tabular}

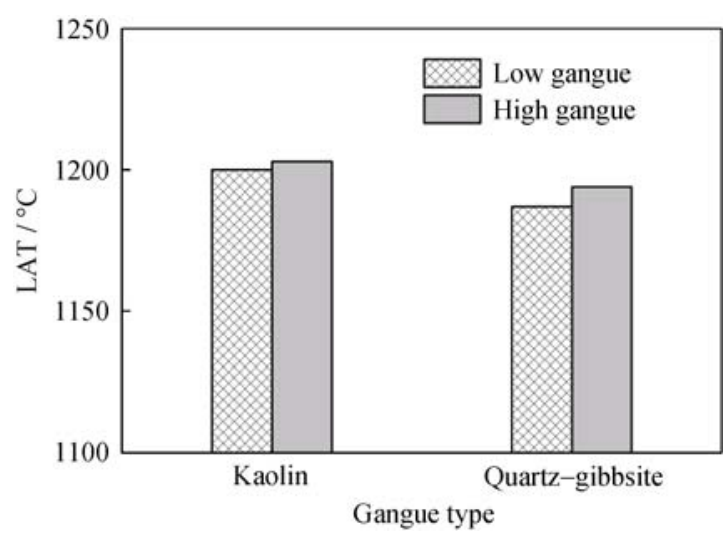

Fig. 11. Results of pure reagent simulating tests.

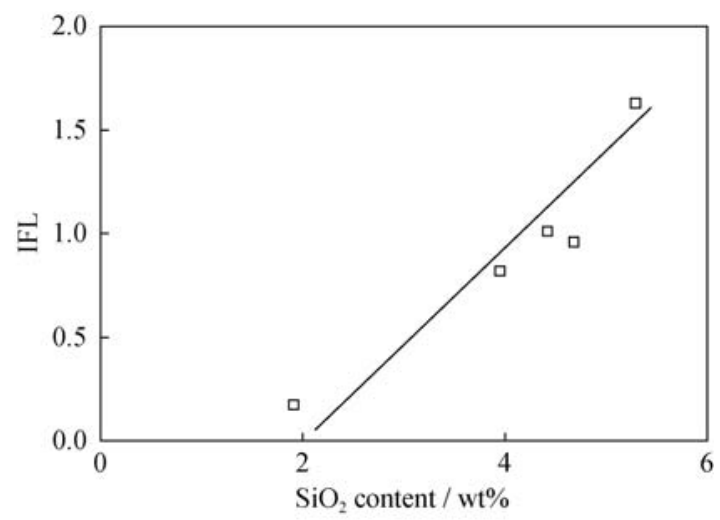

Fig. 12. Relationship between $\mathrm{SiO}_{2}$ content and the IFL of iron ores. 
and the subsequent formation of liquid phase, such as calcium ferrite, may raise the IFL.

Fig. 13 plots the relationship between $\mathrm{Al}_{2} \mathrm{O}_{3}$ content and the IFL of iron ores. Same to the relationship between $\mathrm{Al}_{2} \mathrm{O}_{3}$ content and LAT, the five types of iron ores are separated into two parts by the $\mathrm{Al}_{2} \mathrm{O}_{3}$ content of $1.5 \mathrm{wt} \%$, high $\mathrm{Al}_{2} \mathrm{O}_{3}$ iron ores and low $\mathrm{Al}_{2} \mathrm{O}_{3}$ iron ores. As the $\mathrm{Al}_{2} \mathrm{O}_{3}$ content increases, the IFL decreases in both high $\mathrm{Al}_{2} \mathrm{O}_{3}$ iron ores and low $\mathrm{Al}_{2} \mathrm{O}_{3}$ iron ores. Similarly, Machida et al. [10] found that the viscosity of the mixed iron ore and $\mathrm{CaO}$ increased with increasing $\mathrm{Al}_{2} \mathrm{O}_{3}$ content in four different iron ores. In addition, Wu et al. [3] reported that $\mathrm{Al}_{2} \mathrm{O}_{3}$ had a very high melting point $\left(2050^{\circ} \mathrm{C}\right)$, and it promoted the formation of silicate network structures, which could increase the viscosity of melt, and eventually decrease the fluidity of liquid phase.

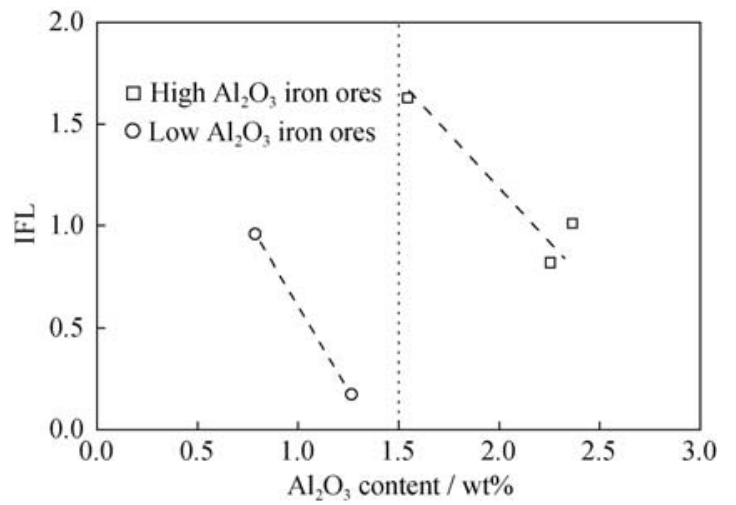

Fig. 13. Relationship between $\mathrm{Al}_{2} \mathrm{O}_{3}$ content and the IFL of iron ores.

The influence of gangue type on the IFL was evaluated in pure reagent simulation tests. Table 3 lists the mixing conditions of the pure reagent mixtures used in the simulating tests. Quartz and gibbsite were simulated by $\mathrm{SiO}_{2}$ and $\mathrm{Al}_{2} \mathrm{O}_{3}$, respectively. The chemical compositions of Sch 1, Sch 2, and $\mathrm{Sch} 3$ were retained constant, i.e., $\mathrm{Fe}_{2} \mathrm{O}_{3}=75.1 \mathrm{wt} \%$, $\mathrm{SiO}_{2}=4.5 \mathrm{wt} \%, \mathrm{CaO}=18.0 \mathrm{wt} \%, \mathrm{Al}_{2} \mathrm{O}_{3}=2.3 \mathrm{wt} \%, \mathrm{MgO}=$ $0.1 \mathrm{wt} \%$, and the basicity was 4.0 . Fig. 14 displays the results of pure reagent simulating tests. The IFL decreases linearly with the gradual replacement of pure reagents $\mathrm{SiO}_{2}$ and $\mathrm{Al}_{2} \mathrm{O}_{3}$ by kaolin, possibly because high- $\mathrm{Al}_{2} \mathrm{O}_{3}-\mathrm{SFCA}$ is formed when $\mathrm{SiO}_{2}$ and $\mathrm{Al}_{2} \mathrm{O}_{3}$ exist as kaolin. Following the simulating tests, the samples were subjected to scanning electron microscopy (SEM) and energy spectrum analysis.

Representative results of the energy spectrum analysis are presented in Fig. 15 and Table 4. The bonding phase and pores in the samples are labeled B and $\mathrm{P}$, respectively. The results reveal that scheme 1 , using quartz and gibbsite, yields low- $\mathrm{Al}_{2} \mathrm{O}_{3}$-SFCA. The highest $\mathrm{Al}$ content in the
SFCA formed under scheme 1 is below $1.90 \mathrm{wt} \%$; however, more $\mathrm{Al}_{2} \mathrm{O}_{3}$ exists in the slag (portion 5 in Fig. 15). On the contrary, scheme 3 using kaolin yields high- $\mathrm{Al}_{2} \mathrm{O}_{3}-\mathrm{SFCA}$. The lowest and highest $\mathrm{Al}$ contents in the SFCA formed under this scheme are $2.2 \mathrm{wt} \%$ and $2.95 \mathrm{wt} \%$, respectively, and rare $\mathrm{Al}_{2} \mathrm{O}_{3}$ is discovered in the slag under scheme 3 .

From the above results, a plausible mechanism can be deduced for the reaction between gangue and other sintering materials. The mechanism is presented in Fig. 16, where $\mathrm{Fe}_{2} \mathrm{O}_{3}, \mathrm{SiO}_{2}, \mathrm{Al}_{2} \mathrm{O}_{3}$, and $\mathrm{CaO}$ are labeled as $\mathrm{F}, \mathrm{S}, \mathrm{A}$, and $\mathrm{C}$,

Table 3. Mixing conditions of mixtures used in the simulating tests

\begin{tabular}{cccc}
\hline Reagent & Scheme 1 & Scheme 2 & Scheme 3 \\
\hline $\mathrm{Fe}_{2} \mathrm{O}_{3}$ & 75.10 & 74.74 & 74.38 \\
$\mathrm{CaO}$ & 18.00 & 17.92 & 17.84 \\
$\mathrm{MgO}$ & 0.10 & 0.10 & 0.10 \\
$\mathrm{SiO}_{2}$ & 4.50 & 3.08 & 1.64 \\
$\mathrm{Al}_{2} \mathrm{O}_{3}$ & 2.30 & 1.16 & 0 \\
$\mathrm{Kaolin}$ & 0 & 3.00 & 6.04 \\
\hline
\end{tabular}

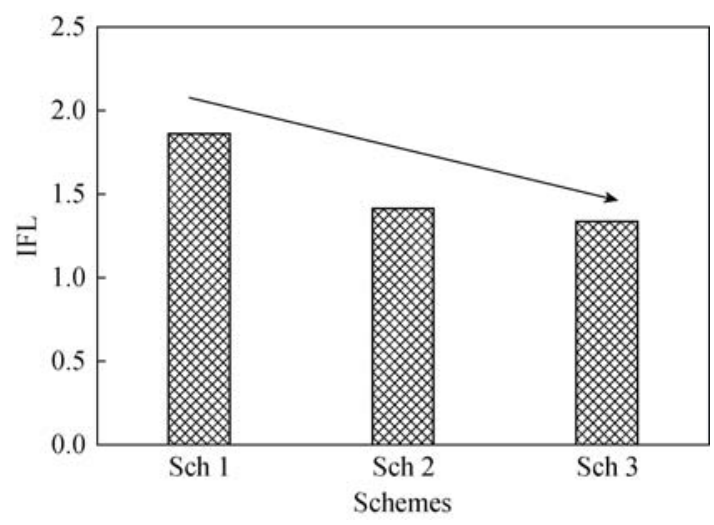

Fig. 14. Results of pure reagent simulating tests.

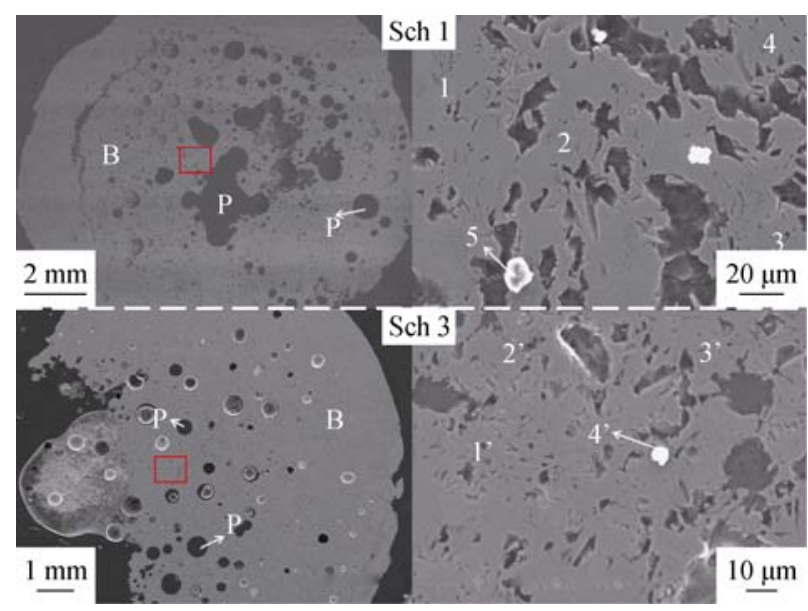

Fig. 15. Identified phases in schemes 1 and 3. 
Table 4. Identified phases in schemes 1 and 3

\begin{tabular}{ccccccccc}
\hline Schemes & Portion & Identified phase & $\mathrm{O}$ & $\mathrm{Al}$ & $\mathrm{Si}$ & $\mathrm{Ca}$ & $\mathrm{Fe}$ & Total \\
\hline \multirow{5}{*}{ Scheme 1} & 1 & SFCA & 29.53 & 0.70 & 0.35 & 15.36 & 54.06 & 100.00 \\
& 2 & SFCA & 28.94 & 1.32 & 0.36 & 14.69 & 54.69 & 100.00 \\
& 3 & SFCA & 29.35 & 1.90 & 0.64 & 12.56 & 55.55 & 100.00 \\
& 4 & SFCA & 28.18 & 1.80 & 1.08 & 13.11 & 55.83 & 100.00 \\
& 5 & Slag & 40.55 & 7.84 & 24.06 & 7.02 & 20.53 & 100.00 \\
\hline \multirow{3}{*}{ Scheme 3 } & $1^{\prime}$ & SFCA & 27.46 & 2.95 & 1.00 & 11.03 & 57.56 & 100.00 \\
& $2^{\prime}$ & SFCA & 26.75 & 2.33 & 2.02 & 12.33 & 56.57 & 100.00 \\
& $3^{\prime}$ & SFCA & 26.34 & 2.22 & 1.42 & 12.16 & 57.86 & 100.00 \\
& $4^{\prime}$ & Slag & 53.02 & 0.24 & 5.93 & 17.94 & 22.87 & 100.00 \\
\hline
\end{tabular}

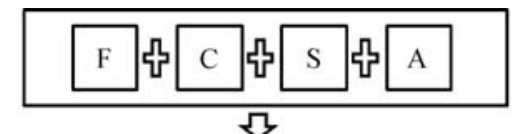

(a)

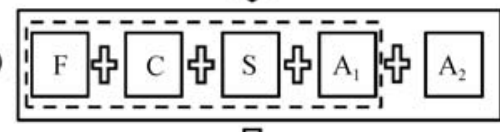

ᄂ?

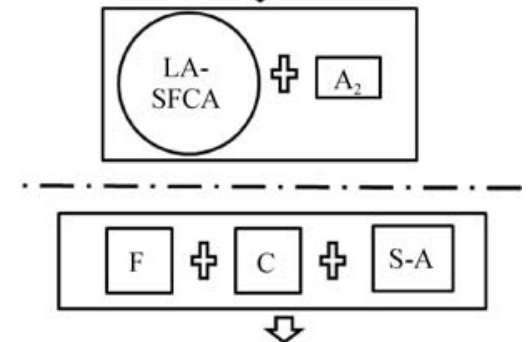

(b)

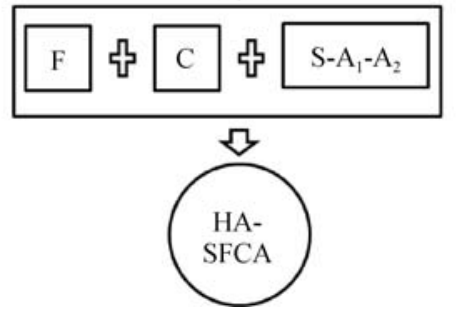

Fig. 16. Reaction mechanism of gangue and other sintering materials.

respectively; $\mathrm{A}_{1}$ and $\mathrm{A}_{2}$ represent the parts of $\mathrm{Al}_{2} \mathrm{O}_{3}$; and LA-SFCA and HA-SFCA represent low- $\mathrm{Al}_{2} \mathrm{O}_{3}-\mathrm{SFCA}$ and high- $\mathrm{Al}_{2} \mathrm{O}_{3}-\mathrm{SFCA}$, respectively. In Fig. 16(a), the gangue existing state is $\mathrm{Q}-\mathrm{G}$, and $\mathrm{Al}_{2} \mathrm{O}_{3}$ and $\mathrm{SiO}_{2}$ are physically separated. In this case, $\mathrm{Al}_{2} \mathrm{O}_{3}$ in the liquid formation reaction is unaffected by $\mathrm{SiO}_{2}$, so the $\mathrm{A}_{1}$-labeled portion of $\mathrm{Al}_{2} \mathrm{O}_{3}$ reacts with $\mathrm{Fe}_{2} \mathrm{O}_{3}-\mathrm{SiO}_{2}-\mathrm{CaO}$ to form low- $\mathrm{Al}_{2} \mathrm{O}_{3}-$ SFCA. Another portion of $\mathrm{Al}_{2} \mathrm{O}_{3}$, labeled $\mathrm{A}_{2}$, becomes involved in other reactions, such as slag formation. By contrast, in Fig. 16(b), the gangue existing state is $\mathrm{K}$, and $\mathrm{SiO}_{2}$ and $\mathrm{Al}_{2} \mathrm{O}_{3}$ are chemically combined. In this case, $\mathrm{Al}_{2} \mathrm{O}_{3}$ in the liquid formation reaction is inevitably influenced by $\mathrm{SiO}_{2}$, so most of the $\mathrm{Al}_{2} \mathrm{O}_{3}$ reacts with $\mathrm{Fe}_{2} \mathrm{O}_{3}-\mathrm{SiO}_{2}-\mathrm{CaO}$, while the excess $\mathrm{Al}_{2} \mathrm{O}_{3}$ infuses into SFCA to form high- $\mathrm{Al}_{2} \mathrm{O}_{3}-\mathrm{SFCA}$. Lu et al. [16] reported that high $\mathrm{Al}_{2} \mathrm{O}_{3}$ content in the calcium ferrite liquid phase increased the viscosity of liquid phase. This likely explains why liquid phase in Fig. 16(b), with kaolin gangue, is less fluid than that in Fig. 16(a), with quartz and gibbsite gangue.

\section{Conclusions}

To elucidate the effect of gangue exiting states on the high temperature characteristics of iron ores, the assimilation characteristics and the fluidity of liquid phase were analyzed by a micro-sintering method in five iron ores with different gangue exiting states. From the results, a putative reaction mechanism of gangue and other sintering materials in the liquid formation process was proposed.

(1) As the $\mathrm{SiO}_{2}$ content increases in the iron ores, the LAT decreases while the IFL increases. In addition, provided that the $\mathrm{Al}_{2} \mathrm{O}_{3}$ content remains below $1.5 \mathrm{wt} \%$, the assimilation reaction is benefited by increasing the $\mathrm{Al}_{2} \mathrm{O}_{3}$ content. Further increase of $\mathrm{Al}_{2} \mathrm{O}_{3}$ content increases the assimilation temperature.

(2) Larger quartz particles in the iron ore can increase the $\mathrm{SiO}_{2}$ content at the local reaction interface between the iron ore and $\mathrm{CaO}$, thereby lowering the LAT.

(3) The quartz-gibbsite gangue is more conducive to the assimilation reaction than the kaolin gangue, because the two gangue classes interact differently with other sintering materials.

(4) Quartz-gibbsite gangues yield low- $\mathrm{Al}_{2} \mathrm{O}_{3}-\mathrm{SFCA}$ with high IFL during the liquid phase formation reaction, while kaolin gangues produce high- $\mathrm{Al}_{2} \mathrm{O}_{3}-\mathrm{SFCA}$ with low IFL.

\section{Acknowledgements}

This work was financially supported by the Fundamental 
Research Funds for the Central Universities of China (No. FRF-MP-12-003B).

\section{References}

[1] S.S. Rath, H. Sahoo, and B. Das, Optimization of flotation variables for the recovery of hematite particles from BHQ ore, Int. J. Miner. Metall. Mater., 20(2013), No. 7, p. 605.

[2] S.L. Wu, Y. Liu, J.X. Du, K. Mi, and H. Lin, New concept of iron ores sintering basic characteristics, J. Univ. Sci. Technol. Beijing, 24(2002), No. 3, p. 254.

[3] S.L. Wu, J.X. Du, H.B. Ma, Y.Q. Tian, and H.F. Xu, Fluidity of liquid phase in iron ores during sintering, J. Univ. Sci. Technol. Beijing, 27(2005), No. 3, p. 291.

[4] L.J. Yan, S.L. Wu, Y. You, Y.D. Pei, and L.H. Zhang, Assimilation of iron ores and ore matching method based on complementary assimilation, J. Univ. Sci. Technol. Beijing, 32(2010), No. 3, p. 298.

[5] S.L. Wu, D. Oliveira, Y.M. Dai, and J. Xu, Ore-blending optimization model for sintering process based on characteristics of iron ores, Int. J. Miner. Metall. Mater., 19(2012), No. 3, p. 217.

[6] L.X. Yang and L. Davis, Assimilation and mineral formation during sintering for blends containing magnetite concentrate and hematite/pisolite sintering fines, ISIJ Int., 39(1999), No. 3, p. 239.

[7] S.L. Wu, Y.M. Dai, D. Oliveira, Y.D. Pei, J. X, and H.L. Han, Optimization of ore blending during sintering based on complementation of high temperature properties, J. Univ. Sci. Technol. Beijing, 32(2010), No. 6, p. 719.

[8] E. Kasai and F. Saito, Differential thermal analysis of assimilation and melt-formation phenomena in the sintering process of iron ores, ISIJ Int., 36(1996), No. 8, p. 1109.

[9] E. Kasai, S.L. Wu, and Y. Omori, Factors governing the strength of agglomerated granules after sintering, ISIJ Int., 31(1991), No. 1, p.17.

[10] S. Machida, K. Nushiro, K. Ichikawa, H. Noda, and H. Sakai, Experimental evaluation of chemical composition and viscosity of melts during iron ore sintering, ISIJ Int., 45(2005), No. 4, p. 513.

[11] L.H. Hsien and J.A. Whiteman, Effect of raw material composition on the mineral phases in lime-fluxed iron ore sinter, ISIJ Int., 33(1993), No. 4, p. 462.

[12] M.S. Xue and X.M. Guo, Effect of $\mathrm{Al}_{2} \mathrm{O}_{3}$ and $\mathrm{SiO}_{2}$ on formation and crystal structure of calcium ferrite containing $\mathrm{Al}_{2} \mathrm{O}_{3}$ and $\mathrm{SiO}_{2}$, J. Chin. Rare Earth Soc., 26(2008), Spec. Iss., p. 205.

[13] N.V.Y. Scarlett, M.I. Pownceby, I.C. Madsen, A.N. Christensen, Reaction sequences in the formation of silico-ferrites of calcium and aluminum in iron ore sinter, Metall. Mater. Trans. B, 35(2004), p. 929.

[14] X.L. Wang, Metallurgy of Iron and Steel, Metallurgical Industry Press, Beijing, 2013, p. 51.

[15] X.M. Guo, Formation and Mineralogy of Calcium Ferrite, Metallurgical Industry Press, Beijing, 1999, p. 153.

[16] L. Lu, R.J. Holmes, and J.R. Manuel, Effects of alumina on sintering performance of hematite iron ores, ISIJ Int., 47(2007), No. 3, p. 349. 